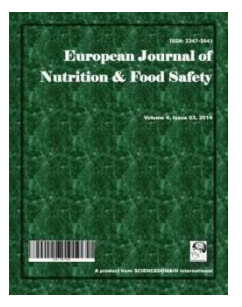

European Journal of Nutrition \& Food Safety

6(2): 58-64, 2016, Article no.EJNFS.2016.008

ISSN: 2347-5641

SCIENCEDOMAIN international

www.sciencedomain.org

\title{
Food Allergy Knowledge, Attitudes and Practices: A Pilot Study of the General Public and Food Handlers
}

\author{
K. Lessa ${ }^{1}$, M. Lozano ${ }^{1}$, M. J. Esteve ${ }^{1}$ and A. Frigola ${ }^{1 *}$ \\ ${ }^{1}$ Department of Nutrition and Food Science, Universitat de València, Avda. Vicent Andrés Estellés s/n \\ 46100 Burjassot, Spain.
}

Authors' contributions

This work was carried out in collaboration between all authors. Authors AF and MJE headed the project. Author KL conducted the analysis and interpretation and drafted the manuscript. Author ML was in charge of data management. All authors were involved in the critical revision of the manuscript for important intellectual content. All authors read and approved the final manuscript.

Article Information

DOI: 10.9734/EJNFS/2016/20696

Original Research Article

Received $4^{\text {th }}$ August 2015

Accepted $13^{\text {th }}$ October 2015

Published $8^{\text {th }}$ December 2015

\section{ABSTRACT}

Objective: We have assessed the factors that might improve the free food allergen at the restaurants. In addition, we have compared food handlers knowledge with the general public knowledge about food allergens.

Design: Cross-sectional, via questionnaires.

Participants: A total of 182 participants (80 food handlers and 102 of general public).

Main Outcome Measures: Dependent variables: Food allergy knowledge, attitudes and practices. Analysis: The analysis of variance (ANOVA) and independent t-test. Questionnaires were hand coded and data was analyzed using Statistical Package for Social Sciences (SPSS) version 19.0.

Results: The survey showed that food handlers and general public had some knowledge on the issue, a major proportion of both group do not believe the meals produced in restaurants are safe in terms of food allergies.

Conclusions and Implications: Allergic people must stay on the alert, questioning the place where they are going to have their meals in terms of the ingredients used, verifying whether the food is really free of allergens. This study can be used by restaurants to develop food allergy policies.

Keywords: Restaurants; food allergy; chefs; general public.

*Corresponding author: Email: ana.frigola@uv.es; 


\section{INTRODUCTION}

The European Academy of Allergy and Clinical Immunology (EAACI) defines the food allergy is a disorder in which a little quantity of food induces an immunological reaction [1]. The symptoms may be severe and many reactions occur within minutes, although could take many hours for them to appear [2]. Similarly to food disorders, food allergies are considered a food and public safety problem, once $2 \%$ of the world adult population shows food hypersensitivity, and nearly $1 \%$ suffers from food allergy per se [3]. In Europe, 17 million people have sort of food allergy. In Spain, updates data on the prevalence among the general population does not be available, but the food allergy has been growing, among the general population does not be available, but the food allergy has been growing, has already doubled the numbers of diagnostics in little more than a decade, which growing the prevalence from $3,6 \%$ in 1992 to $7,4 \%$ in 2005 , in accordance with the results of the epidemiology survey of Spanish Society of Clinical Allergology and Immunology (SEAIC) [4]. Unlike the food intolerance that involves digestive enzymes and may result in abdominal pain, gas and swelling, the severe reactions caused by food allergies are responsible for around 30,000 cases of medical emergency and 150-200 deaths per year in the United States [5,6].

One of the most challenging aspects of allergen free diet is eating foods away from home, particularly in restaurants [7,8]. The European Commission recognises that seven out of ten allergic reactions serious occur when people eat away from home [4]. However, a survey of 100 restaurant managers, chefs and servers, found that only $42 \%$ had received some food allergy training [9].

The quality of life has been described as embracing health-related perspectives including social, emotional, and physical well-being [10]. If diet limits or in any way affects the ability to dine out and travel, it impacts a person's life [11]. There is no information as to the level of awareness of either the general public or managers, chefs and servers in Spain about the food allergen related health issues. We therefore surveyed both food handlers and members of the general public about their knowledge of food allergen.

\section{MATERIALS AND METHODS}

The surveys assessed the knowledge of food allergens in the general public and food handlers.
The survey given for both group was modified from a survey used in a previous similar study [12] and assessed awareness of food allergens, attitudes, knowledge, and practices of them. The questionnaire was comprised of 10 questions (Table 1) that included general strategies and specific methods for reducing allergy crises, training, safety in food preparation and knowledge on food allergens.

The initial survey was conducted in 15 restaurants in downtown of Valencia-Spain and representing a total of 80 food handlers including cooks, kitchen assistants, and service assistance. Each food unit had at least four food handlers and at most eight. The following services were provided by these establishments: lunch and dinner. The supervisors of each unit were first contacted, and their authorization requested to conduct the survey. After obtaining the authorization, each unit was visited and the food handlers informed about the theme of the survey and how they should proceed when they received the questionnaires. It was explained that they did not need to reveal their identity. After completing the questionnaires, the food handlers were supposed to mail them back to the addressee.

The survey given to the general public was used the same questionnaire from food handlers, and assessed awareness of food allergens. The general public was recruited at the restaurants selected for this pilot study by face-to-face interviews and representing a total of 102 people.

A convenience sample was presented to 182 food handlers and general public. Convenience sampling occurs when members of the respondent population are chosen based on their relative ease of access, in this case those food handlers and general public present at the restaurants and willing to complete a survey [13].

Comparisons between food handlers and the general public were performed using the analysis of variance (ANOVA) and independent t-test were used to examine significant differences in food allergy knowledge, attitudes and practices. Questionnaires were hand coded and data were analyzed using Statistical Package for Social Sciences (SPSS) version 19.0.

\section{RESULTS AND DISCUSSION}

Table 1 shows the results. Although the chefs perceived that they had a good knowledge of food allergens, as indicated by the results, they 
possess no much more than the average general public ( $\mathrm{t}=-1.9707, \mathrm{df}=169.9, \quad P=0.050)$. Significantly, the chefs' ability to construct freeallergens menus and indeed cook safe is brought into question.

In our study $56,4 \%$ the general public, related had any knowledge of food allergens) and $67 \%$ of food handlers related had some knowledge of food allergens. However, comparing the answers of the question $1,51,2 \%$ of food handlers had not plan to produce safe food in terms of allergens, which their knowledge may reflect their remembering on some part of good hygienic practices training. Of the general public interview $73,3 \%$ answered had any plan to produce safe food in terms of allergens, although it could be questioned where they believed they had gained this knowledge.

In the $5^{\text {th }}$ question, the knowledge of food handlers and general public if the amounts of a food know to contain an allergen may lead or not to food allergies was evaluated. Among food handlers the rate of "no" answers was of $82,9 \%$, while among general public the rate of no answers was $83,2 \%$ if someone presenting allergic reactions could or not consume small amounts of to carry allergenic compounds. Whether the client have a food intolerance, an IgE-mediated food allergy or celiac disease, diagnosed individuals will need to avoid consuming foods which may trigger symptoms. For the most sensitive people, this will even include traces of the allergen which may be found in other dishes or products and, in some cases, other forms of contact, e.g. via the skin or by inhalation [14].

The dietary habits of a region and the methods used to prepare the food play an important role in the predominance of food allergies in many countries around the world. Most reactions are caused by food ingestion, but the steam and smoke originated from the cooking process may contain allergens which can be inhaled [7]. The cooking process may reduce the allergenicity of certain proteins in the food, but heating can increase the allergenicity of other proteins by inducing covalent changes that lead to the production of new antigens or improve the stability of existing ones [15].

Table 1. The perception of general public and food handlers regarding food allergies

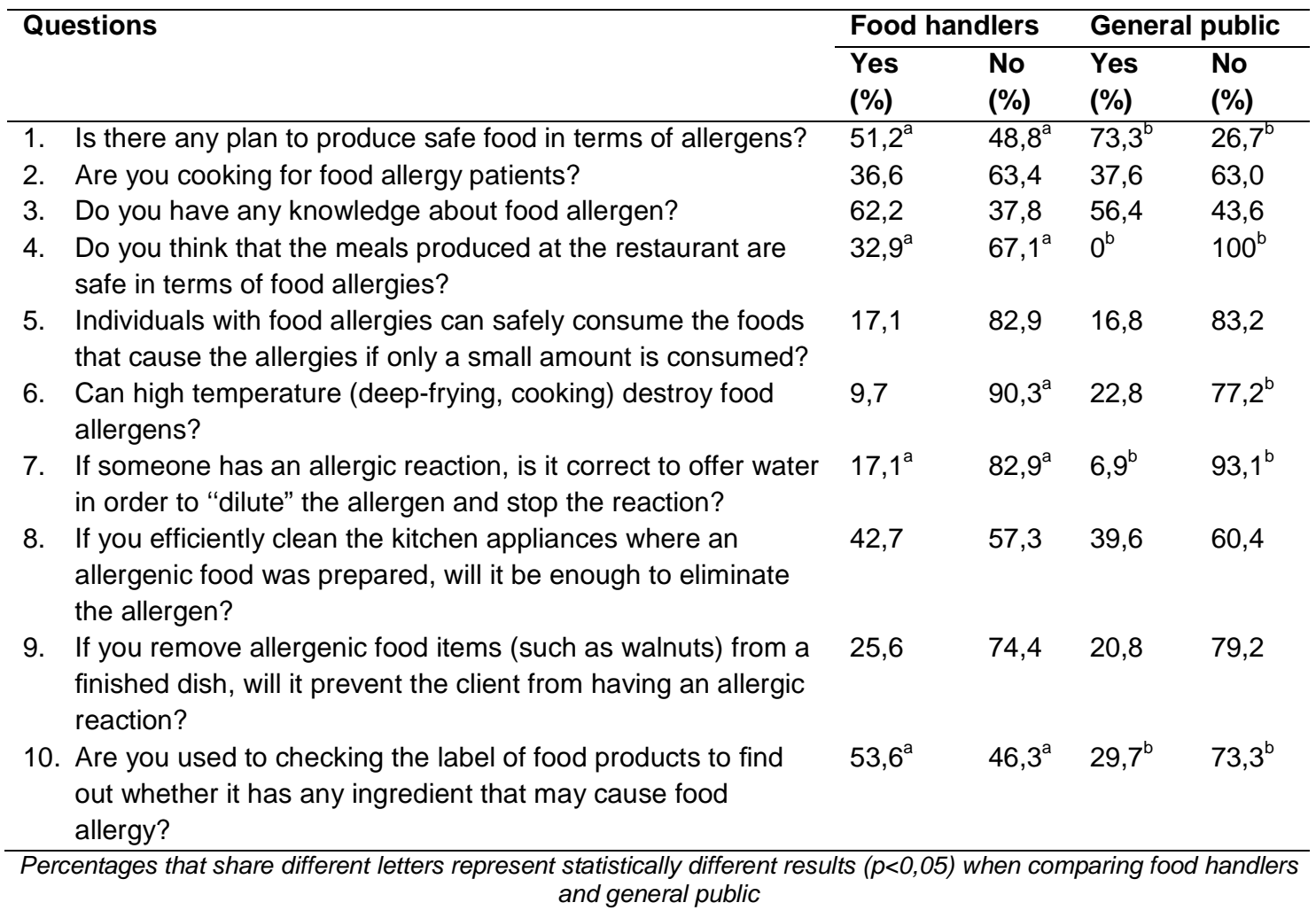


In the present study, most of food handlers $(90,3 \%)$ and general public $(77,2 \%)$ agreed that high temperatures might not be sufficient to destroy the allergen $(P=0,014)$.

Of the food handlers and general public interviewed, $82,9 \%$ and $93,1 \%$ answered that they did not know if it was the right thing to offer water to someone suffering from an allergic reaction with the purpose of "diluting" the allergen and stopping the crisis. However, when we asked the managers about equipped to handle food allergy emergencies including the used of self-injectable epinephrine all reported no knowledge about. Previous research has shown that food handlers lacking in knowledge about food allergies were more likely to handle food allergy emergencies or to address the needs of allergic customers inappropriately [16] and including not carrying self-injectable epinephrine $[17,18]$. Weiss and Munoz-Furlong [7] many foodservice establishments were ill-equipped to handle food allergy emergencies [19].

It can be seen in the 8th question, $60,4 \%$ of the general public do not believe that the appropriate hygiene of appliances used in the meals would be an effective measure to eliminate traces of allergenic foods that could interfere in the health of another client in the preparation of a different food. Among food handlers, a rate of $57,3 \%$ do not believe that cleaning would be an effective measure to eliminate allergens from kitchen appliances. Regarding the $9^{\text {th }}$ question, $25,6 \%$ and $20,8 \%$ of general public and food handlers respectively, believed that removing food items that cause allergy from a finished dish would prevent the allergic client from having any kind of reaction. This result is of great concern, foodservice employees might cause crosscontact, which could cause serious harm to food allergy sufferers [20]. Thus, foodservice operations should educate employees about the eight allergens that (peanuts, tree nuts, milk, eggs, fish, shellfish, soy, and wheat) account for $90 \%$ of all food-based allergic reactions [21]. However, foodservice employees should also be made aware that food allergies are not limited to the top eight allergens and customers may have allergies to any food item, thus all allergy requests should also be handled with the same amount of caution. Additionally, respondents had the lowest rating on food allergy practice related to cross-contact. Cross-contact is the accidental contact between allergen and non-allergen foods, which may occur at any stage of the production and storage process (after the products are packed). This usually happens with the transfer of allergenic proteins when the food is processed or handled, especially when multiple ingredients or food items are produced on the same production line as other items that are non-allergenic or that contain another type of allergenic protein [22]. Cleaning of equipments and appliances contacting foods is an important route of food contamination with allergens. In the food industry, bad formulation, inappropriate hygiene and cross-contamination with dust or parts of allergens (fragments of peanuts, for example) left in the processing system are potential means for an allergen to contaminate an unrelated product. In this case, in order to guarantee the safety of processes, it is necessary to identify the potential points of contamination and establish a prevention system [23]. Thus, the use of equipment to produce food requires well-defined and consistent cleaning techniques, especially if the same equipment is used to prepare several types of product. furthermore Ahuja and Sicherer [10], found that foodservice employees confused crosscontamination with cross-contact. Cross-contact is the accidental contact between allergen and non-allergen foods, while cross-contamination is the contact between raw and cooked foods, the latter relates to microbial contamination [24]. Therefore, catering services should clearly define the Good Manufacturing Practices to their employees. However, patrons with food allergies should also alert foodservice staff about their food allergies when dining at foodservice establishments and share the responsibility of preventing incidences of food allergies.

A total of $46,35 \%$ of food handlers and $73,30 \%$ of general public did not have the habit of reading food labels to check whether there was any ingredient that might cause a food allergy. This is alarming and highlights the need for periodic training practices. Food labeling is an important support for consumers, providing them with the opportunity of knowing the product composition, safely ingesting nutrients and energy, as well as obtaining important information concerning the maintenance of their health [25]. In the case of allergens, it is essential that labels contain accurate information, even if the presence of traces or the remote risks of traces result in reduced consumption of the products [3]. A study performed with allergic volunteers and parents of allergic children in Greece and the Netherlands in order to verify their behavior towards labeling when shopping for food, concluded that the labeling standards were highly unsatisfying. In 
general, the participants complained about the complexity of the information, its position on the label, its format and packaging changes, amongst others [26].

$4^{\text {th }}$ question (Table 1), the majority of food handlers $(67,08 \%)$ answered that they disagree the meals produced in their restaurants are safe in terms of food allergies. The lack of confidence in handling a situation could also be because respondents had never received training specific to food allergies $[12,6]$. These results are consistent with previous research [27], that found that employees with food safety certification had more confidence in implementing food safety programs in their workplace than those employees that did not have certification. In the European Union Code 1169/2011- R.D. $852 / 20042004$ coming into force $13^{\text {th }}$ of December 2014, it is mandatory that internal training and organizing training courses, necessary to implement the new process food labeling and customer information in the field of food allergens. This study was done before the Food Information for Consumers Regulation (1169/2011) was fully implemented, and does not measure the impact of the Regulation in the restaurants services, but draws attention to the points must take account. There are a number of barriers in implementing food allergy training such as cost of training employees, high turnover, time restrictions, language problems, and employees' apathy toward food allergies [28]. Furthermore [29], highlights the need for providing training at regular intervals to reinforce food safety concepts, provide updated information and increasing confidence among staff members. Training may be provided either formally (classroom) and informally (info sheets, flyers posted in preparation and service areas) that reinforces training concepts. Chapman et al. [30] found that posting of food safety info sheets in prominent locations within a foodservice establishment positively influenced food safety behaviors.

Among general public, a value of $100 \%$ answered that they disagree the meals produced in restaurants are safe in terms of food allergies. When we compared with similar study by Karajeh, et al. [31] from an British population when questioned about their frequency of eating food not prepared at home, coeliac disease patients were less likely to eat take away food or dine at a friends' house, when compared to the general public. In the meantime those patients with celiac disease are comfortable dining out if they frequent the same restaurant. This may allow them to become familiar with that chef and be reassured that this establishment will provide a gluten-free meal. It is important for food suppliers to understand who is buying food for people with coeliac disease, food intolerances and allergies and what they need. This can be achieved by maintaining close links with relevant consumer / patient groups and also keeping up to date with scientific, clinical, social and other consumer research and with relevant legislation, industry standards and voluntary guidance. Early work to reduce risks and improve food allergen avoidance for consumers began in the UK in the mid-1990s [25] and involved producers, manufacturers, retailers, caterers, regulators, scientists and consumers supported by expert allergy clinicians. From the start it was recognised that improved allergen management and accessible consumer information depend on the engagement and understanding of key people throughout the food supply chain.

There are several limitations of our study. It was conducted in Valencia where the demand for free food allergy, and awareness, may be different to other areas of the Spain. This information would have proved helpful in determining whether restaurant avoidance was widespread throughout the country. The food handlers and general public that completed the survey may not have been representative of food handlers and general public throughout the Spain due to the nature of recruitment. A larger study of face-to-face or telephone interviews of chefs and general public nationwide would be beneficial.

\section{CONCLUSION}

This study provided information about food allergy knowledge, attitudes, practices, training received, and perceived training needs of food handlers and general public. Even though the survey showed that food handlers and general public had some knowledge on the issue, a major proportion of respondents do not believe the meals produced in their restaurants are safe in terms of food allergies, understandably, when one considers that chefs have varying knowledge of food allergies. Allergic people must stay alert, questioning the place where they are going to have their meals in terms of the ingredients used, verifying whether the food is really free of allergens, and always observing the labels of food products.

Educating chefs about food allergens may alleviate the social restrictions on allergic people and, restaurants should work toward providing 
not only food safety training as it relates to preventing microbial contamination but also provide training specific to food allergies.

Results from this study can be used by restaurants to develop food allergy policies and procedures by taking into account the needs of their food handlers to protect food allergy sufferers in restaurants and promote customers well-being.

\section{COMPETING INTERESTS}

Authors have declared that no competing interests exist.

\section{REFERENCES}

1. Alvarado MI, Pérez M. Study of food allergy on Spanish population. Allergol, et al. Immunopathol. 2006;34(5):185-93.

2. Food Safety Authority of Ireland. Allergens. Available: <http://www.fsai.ie> Accessed 20.04.09.

3. International Life Sciences Institute ILSI. Alergia alimentar. ILSI Europe Concise Monograph Series. Willian F. Jackson. ILSI. 2003;40.

4. Sociedad Española de Alergología e Inmunología Clínica- SEAIC. Resumen del libro de las enfermedades alérgicas y del tratado de alergología; 2012.

Available: http://www.seaic.org/

5. Hunter B. Alergias alimentarias. Gastroenterologia Latinoamericana. 2007; 18:144-151.

6. Weiss C, Munoz-Furlong A. Fatal food allergy reactions in restaurants and foodservice establishments: Strategies for prevention. Food Protection Trends. 2008; 28(9):657-661.

7. Lee A, Newman JM. Celiac diet: Its impact on quality of life. J Am Diet Assoc. 2003; 103:1533e5.

8. Cranney A, Zarkadas M, Graham ID, Butzner JD, et al. The Canadian celiac health survey. Dig Dis Sci. 2007;52: 1087 e95.

9. Ahuja R, Sicherer SH. Food-allergy management from the perspective of restaurant and food establishment personnel. Ann Allergy Asthma Immunol 2007;98:344-8.

10. Lohiniemi S, Mustalahti K, Collin P, Maki M. Measuring quality of life in coeliac disease patients. $9^{\text {th }}$ International Symposium on Celiac Disease; Tampere, Finland; 1998.
11. Green SN, Stavropoulos PHR, Pangagi SG, Goldstein SL, McMahon DJ, Absan H, Neugut Al. Characteristics of adult celiac disease in the USA: Results of a national survey. Am J Gastroenterol. 2001;96: 126-131.

12. Ajala AR, Cruz AG, Faria JAF, Walter $E H M$, et al. Food allergens: Knowledge and practices of food handlers in restaurants. Food Control. 2010;21(10): 1318-1321.

13. García-García JA, Reding-Bernal A, López-Alvarenga JC. Cálculo del tamaño de la muestra en investigación en educación médica. Investigación en Educación Médica. 2013;2(8):217-224.

14. Gowland $\mathrm{MH}$. Handbook of Food Allergen Detection and Control; 2015.

Available:http://dx.doi.org/10.1533/978178 2420217.1.133

15. Mansueto P, Montalto G, Pacor ML, Esposito-Pellitteri et al. Food allergy in gastroenterologic diseases: Review of literature. World Journal of Gastroenterology. 2006;12(48):77447752.

16. Madsen $\mathrm{CB}$, Crevel $\mathrm{R}$, Chan $\mathrm{CH}$, Dubois AEJ, et al. Food allergy: Stakeholder perspectives on acceptable risk. Regulatory Toxicology and Pharmacology. 2010;57:256e265.

Available:http://dx.doi.org/10.1016/i.yrtph.2 $\underline{010.03 .003}$

17. Greenhawt MJ, Singer AM, Baptist AP. Food allergy and food allergy attitudes among college students. Journal of Allergy and Clinical Immunology. 2009;124: $323 \mathrm{e} 327$.

Available:http://dx.doi.org/10.1016/j.jaci.20 09.05 .028

18. Rolison MR, Scherman A. College student risk-taking from three perspectives; 2002. Available:http://findarticles.com/p/articles/ mi m2248/is 152 38/ai n6028029/

19. Choi JH, Rajagopal L. Food allergy knowledge, attitudes, practices, and training of foodservice workers at a university foodservice operation in the Midwestern United States. Food Control. 2013;31:474-481

20. Mandabach $\mathrm{KH}$, Ellsworth A, Vanleeuwen DM, Waters HL. Restaurant manager's knowledge of food allergies: A comparison of differences by chain or independent affiliation, type of service and size. Journal of Culinary Science \& Technology. 2005; 4(2/3):63e77. 
21. Food Allergy and Anaphylaxis Network. Welcome guests with food allergies; 2010. Available:http://www.foodallergy.org/files/ WelcomingGuests2010.pdf

22. Jackson LS, Al-Taher FM, Moorman M, DeVries JW, et al. Cleaning and other control and validation strategies to prevent allergen cross-contact in food-processing operations. Journal of Food Protection. 2008;71(2):445-458.

23. Deibel K, Traumant T, Deboom T, Sveum $\mathrm{WH}$, et al. Comprehensive approach to reducing the risk of allergens in foods. Journal of Food Protection. 1997;60: 436-441.

24. ServSafe Coursebook. ServSafe Coursebook ( $6^{\text {th }}$ ed.). Chicago: IL: The National Restaurant Association Educational Foundation; 2012.

25. Gowland $\mathrm{MH}$. Handbook of food allergen detection and control. A volume in Woodhead Publishing Series in Food Science, Technology and Nutrition. 2015; 133-160.

26. Voordoum J, Voordouw J, CornelisseVermaat JR, Yiakoumaki V, et al. Food allergic consumer's preferences for labelling practices: A qualitative study in a real shopping environment. International Journal of Consumer Studies. 2009;33(1): 94-102.
27. Youn S, Sneed J. Implementation of HACCP and prerequisite programs in school food service. Journal of the American Dietetic Association. 2003;103: $55 \mathrm{e} 60$.

Available:http://dx.doi.org/10.1053/iada.20 03.50002

28. Abbot JM, Byrd-Bredbenner C, Grasso D. "Know before you serve": Developing food allergy factsheet. Cornell Hospitality Quarterly. 2007;48:274e283.

Available:http://dx.doi.org/10.1177/001088 0407302779

29. Madsen $\mathrm{CB}$, Crevel $\mathrm{R}$, Chan $\mathrm{CH}$, Dubois AEJ, DunnGalvin A, Blok BMJF, et al. Food allergy: Stakeholder perspectives on acceptable risk. Regulatory Toxicology and Pharmacology. 2010;57:256e265.

Available:http://dx.doi.org/10.1016/j.yrtph.2 010.03 .003

30. Chapman B, Eversley T, Fillion K, MacLaurin T, Douglas P. Assessment of food safety practices of foodservice food handlers (risk assessment data): Testing a communication intervention (evaluation of tools). Journal of Food Protection. 2010; 73(6):1101e1107.

31. Karajeh MA, Hurlstone DP, Patel TM, Sanders DS. Chefs' knowledge of celiac disease (compared to the public): A questionnaire survey from the United Kingdom. Clin Nutr. 2005;24:206e10.

(c) 2016 Lessa et al.; This is an Open Access article distributed under the terms of the Creative Commons Attribution License (http://creativecommons.org/licenses/by/4.0), which permits unrestricted use, distribution, and reproduction in any medium, provided the original work is properly cited. 